\title{
Cat-and-mouse over \\ the French nukes
}

French nuclear tests and the controversial draft Pacific logging code of practice drew most of the media coverage at the Madang South Pacific Forum meeting. But logging was almost brushed aside by the host country.

\section{BY EKONIA PENI}

OF ALL the issues that emerged from the 26th South Pacific Forum in Madang in September, I thought the resumption of nuclear testing by France received most coverage over the position the leaders took. I can also argue that the logging issue attracted a fair share of the media coverage.

But the first official statement from the Forum relating directly to French nuclear testing has left unanswered questions. After their Jais Aben retreat, the Forum leaders 'bomb blasted' France for its resumption of tests and warned that, 'should France continue its testing in the Pacific, the Forum will review France's status as a post- Forum dialogue partner'. The mass media gave this a good wrap up to inform the international community that the Pacific leaders have made a strong commitment on the nuclear testing issue.

However, what the media considered as 'balance' from the non-government organisation parallel forum was the statement by Greenpeace's Bunny McDiarmid, who said the Forum leaders should back up their strong statement with equally strong action - not 'strong rhetoric and weak action'.

As the Forum ended, the general media observation on nuclear testing was that a game of cat-and-mouse had started between the Forum leaders and France. This was because of the many unanswered questions that have emerged from the Forum. Among them: when will France conduct its next test? What sort of action will the leaders take after they have reviewed France's status?

And what will happen to France in that review in light of its strongholds in its Pacific territories of French Polynesia and New Caledonia?

Yet the logging issue almost became insignificant with the leaders almost letting this 'big fish' get away. But this timber fish never actually got away because the media succeeded in forcing Forum leaders to keep it on their agenda. 140 PACIFIC JOURNALISM REVIEW 2:1 1995 


\section{EKONIA PENI}

What did the media do? Well, after the officials meeting, Foreign Affairs and Trade Secretary Gabriel Dusava briefed me and my local colleagues, Jonathan Tannos (Post Courier) and Robyn Sela (Nau FM), saying the code of conduct on logging would not be signed or endorsed since some countries were 'not ready'.

Our coverage on the issue drew strong reaction from Australia's Prime Minister, Paul Keating, who wanted the code to be endorsed. Keating's reaction was bitter medicine which PNG and its major logging industry neighbour, the Solomon Islands, could not swallow.

The official response from the NGO parallel forum was in itself extra bitter which the Forum leaders could not take. The media coverage on these reactions no doubt placed more pressure on leaders to do what was doubtful at first - and in the end they endorsed the code of conduct on logging. But both Papua New Guinea and the Solomons indicated they were reluctant to put it into effect. I thought his media coverage of the logging issue was the most successful reporting that emerged from the Madang Forum.

On the personality front, Madang Governor Peter Barter receives my vote of thanks for supporting the local media, especially NBC.

$\square$ Ekonia Peni is a senior NBC journalist assisting SPCenCIID. He was covering the Forum for a daily current affairs program and this article is reprinted from his 'Mediawatch' column in Uni Tavur on 29 September 1995. 